\title{
Síndrome coronario agudo por hipersensibilidad: Síndrome de Kounis
}

\author{
Acute coronary hipersensitivity disorder: Kounis Syndrome
}

\author{
Francisco Pampín ${ }^{1}$, Manuel Jorge Rial Prado², Rocío Vázquez Vigo³ , Luis Alfredo González Guzmán² \\ ${ }^{1}$ Unidad de Cuidados Intensivos, ${ }^{2}$ Servicio de Alergología, ${ }^{3}$ Servicio de Medicina Interna. \\ Complejo Hospitalario Universitario A Coruña. SERGAS. A Coruña
}

\begin{abstract}
Resumen
El síndrome de Kounis (SK) es una nueva entidad clínica definida como la aparición simultánea de síntomas alérgicos y de un síndrome coronario agudo. Desde su descripción inicial en el año 91 se han ido sumando revisiones y descripciones de casos que están permitiendo conocer mejor su patogénesis. Desde el año 2010 se han definido tres variantes de dicho síndrome: angina alérgica vasoespástica (tipo I), infarto de miocardio alérgico (tipo II) y trombosis intrastent con trombo oclusivo infiltrado por eosinófilos y mastocitos.
\end{abstract}

En el presente artículo describimos un caso de SK tipo I y otro caso de SK tipo II, discutiendo acerca del tratamiento pautado en dichos casos.

Palabras clave. Anafilaxia. Síndrome de Kounis. Metamizol. Alergia a medicamentos.

\section{Introducción}

El síndrome de Kounis, angina alérgica o infarto de miocardio alérgico, fue descrito en 1991 por Kounis y Zavras como la aparición de manera simultánea, de eventos coronarios agudos y síntomas alérgicos anafilácticos / anafilactoides ${ }^{1}$. Actualmente hay descritos en la literatura tres subtipos, el tipo I sin enfermedad coronaria, el tipo II con enfermedad coronaria y el tipo III en pacientes que sufren trombosis de un stent farmacoactivo ${ }^{1,2}$. En la actualidad continúa siendo poco conocido con cerca de unas 100 entradas en Pubmed. La epidemiología es desconocida y no existen guías de práctica clínica que establezcan el tratamiento de elección. Presentamos dos casos clínicos de este síndrome diagnosticados en nuestro centro.

\section{Caso clínico}

El primer caso es un varón de 80 años sin alergias conocidas con antecedentes de HTA, Obesidad, Miocardiopatía hipertrófica, VHC, IRC y úlcera gástrica intervenida hace más de treinta años que tras caída casual sufre rotura de $8^{\mathrm{a}}$ y $9^{\mathrm{a}}$ costillas por lo que le pautan metamizol. Tras la toma de la primera dosis de metamizol sufre disnea súbita, dolor costal e interescapular no irradiado, exantema maculopapular generalizado, palpitaciones y sudoración. Cuando llega a Urgencias presenta tensión arterial de 90/60 mmHg, con frecuencia cardiaca de 180 latidos por minuto, se encuentra taquipneico a 30 respiraciones por minuto y se auscultan crepitantes en ambas bases pulmonares. El electrocardiograma realizado en ese momento muestra una taquicardia supraventricular a 180 latidos por minuto con bloqueo completo de rama derecha sin datos de isquemia. Se administran en urgencias hidrocortisona, dexclorfeniramina, volumen intravenoso y fentanilo con resolución de la taquicardia y de la clínica respiratoria. Se comprueba que la Troponina I aumenta en seis horas de 0,14 a $163 \mathrm{ng} / \mathrm{mL}$.

\begin{abstract}
Kounis syndrome is a new clinical entity defined as the occurrence of acute coronary syndromes caused by inflammatory mediators. It was first described in 1991, and since then, new individual case description is helping to delineate its pathogenesis and treatment. Three variants of Kounis syndrome have been described: vasospastic allergic angina (type I), allergic and atheromatous myocardial infarction (type II), and coronary artery stent thrombosis demonstrating the presence of eosinophils and mast cells (type III).
\end{abstract}

Two new cases of type I and type II Kounis syndrome are presented emphasizing its distinct treatment dilemmas.

Key words. Anaphylaxis Kounis syndrome. Metamizol. Drug allergy.

Asimismo los niveles de triptasa a las tres horas del comienzo de la sintomatología fueron de 32,7 $\mu \mathrm{g} / \mathrm{L}$ siendo de $9,74 \mu \mathrm{g} / \mathrm{L}$ a las 48 horas de iniciado el cuadro. Se realiza ecocardiograma transtorácico que es similar al previo sin que se evidencien alteraciones de la contractilidad globales o segmentarias. Tras ser tratado en el Servicio de Urgencias se decide ingreso en unidad de cuidados intensivos para monitorización y vigilancia, donde realizan ecocardiograma transesofágico con mismo resultado que el anteriormente descrito y coronariografía sin que se demuestre patología en arterias coronarias. Tras 48 horas en UCI con buena evolución clínica se decide traslado a planta convencional con diagnóstico de Síndrome de Kounis tipo I.

El segundo caso es una mujer de 90 años con antecedente de alergia a quinolonas, diabetes mellitus tipo II e historia conocida de cardiopatía isquémica con IAM en el año 2007 y revascularización completa en circunfleja proximal y coronaria derecha. Por dolor osteoarticular su médico de cabecera le prescribe metamizol y a los pocos minutos de la toma del mismo, comienza con prurito palmar, angioedema facial, disnea y eritema generalizado motivo por el que acude a Urgencias de nuestro centro. Se le administran 200 miligramos de hidrocortisona, dexclorfeniramina y 40 miligramos de metilprednisolona por vía endovenosa con rápida mejoría clínica. Mientras se encuentra en Urgencias, a las dos horas del inicio de la sintomatología, comienza con dolor centrotorácico, definido como un peso e irradiado a cuello y hombro izquierdo que cede a los cinco minutos sin tratamiento. En el ECG se evidencian ondas T negativas en II, III y aVF presentes en estudios previos sin otros cambios. En ese momento se le extrae sangre para analizar y se solicita troponina seriada y triptasa con resultados de 2,06 (pico máximo) y 27,5 (a las dos horas del inicio de la reacción) respectivamente. Se decide ingreso de la paciente en planta convencional de medicina interna con diagnóstico de Síndrome coronario agudo sin elevación del segmento ST tipo infarto agudo de miocardio no q y anafilaxia por metamizol. Durante su hospitalización es tratada con metilprednisolona y dexclorfeniramina hasta resolución 
de síntomas cutáneos y con beta-bloqueantes, heparina, aas, nitratos y clopidogrel para los síntomas cardiacos con buena evolución clínica siendo dada de alta en 6 días. Una vez dada de alta es vista en consultas externas de alergología donde se solicita una determinación de triptasa basal con resultado de 3 y se diagnostica de Síndrome de Kounis tipo II secundario a alergia a Pirazolonas.

\section{Discusión}

El Síndrome de Kounis es una enfermedad con epidemiología desconocida e infradiagnosticada. En los casos presentados se ha llegado al diagnóstico por sospecha clínica ya que se han podido objetivar síntomas alérgicos agudos coincidentes en el tiempo con eventos coronarios. Típicamente los pacientes presentarán, tras la exposición a un agente con potencial alergénico conocido, síntomas coronarios referidos como malestar, angina, sudoración... y de manera simultánea el abanico de síntomas de una reacción alérgica aguda (hipotensión, lesiones urticariales, prurito, angioedema, síntomas respiratorios, síntomas digestivos) ${ }^{3}$. Cualquier fármaco podría desencadenar un síndrome de Kounis, con especial precaución con los derivados beta-lactámicos, en segundo lugar los AINEs y dentro de los mismos las pirazolonas son especialmente alergénicas; ocuparían el tercer lugar los anestésicos generales y en menor medida los medios de contraste radiológicos ${ }^{1-4}$.

La etiología de este síndrome no se conoce en la actualidad y se postula la implicación de los mediadores mastocitarios como histamina, serotonina, triptasa, quimasa y leucotrienos como agentes vasoactivos capaces de generar un vasoespasmo coronario 0 angina microvascular en el SK tipo I y de erosionar una

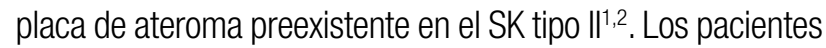
con Síndrome de Kounis tipo III padecen trombosis de stents farmacoactivos y la tinción con hematoxilina-eosina y Giemsa demuestra la presencia de mastocitos y eosinófilos ${ }^{5}$.

El marcador inmunológico utilizado en ambos casos para apoyar la sospecha clínica es la determinación de B-triptasa, mediador liberado desde los mastocitos en paralelo con la histamina, con un pico entre los 15-120 minutos desde la activación por el estímulo alergénico. La triptasa es un buen indicador de la presencia de descarga masiva de mediadores procedentes de mastocitos $^{6}$. Los altos niveles de triptasa junto con síntomas alérgicos apoyan la sospecha de la implicación farmacológica como desencadenante del cuadro en los dos casos presentados, puesto que no en todas las anafilaxias tiene por qué elevarse los niveles de triptasa como es el caso de las de origen alimentario.

El tratamiento del SK es controvertido puesto que no hay guías clínicas en la actualidad, aunque los calcios antagonistas y los nitratos se han postulado como los fármacos de primera elección para tratar los síntomas cardiacos; evitando los nitratos en casos de hipotensión y/o taquicardia. La oxigenoterapia no se discute en casos de SCA o anafilaxia que presenten hipoxemia. La fluidoterapia estaría indicada bajo monitorización hemodinámica. En todos los tipos de síndrome de Kounis es adecuado el uso de hidrocortisona a dosis de 1-2 mg/kg/día y de antihistamínicos $\mathrm{H} 1$ y H2 a dosis máxima (dexclorfeniramina $5 \mathrm{mg} / 6$ horas y ranitidina $50 \mathrm{mg}$ cada 6 horas). En ninguno de los casos clínicos presentados se utilizó adrenalina para tratar los síntomas a pesar de ser el fármaco de elección para tatar la anafilaxia según la guía Galaxia. El empleo de adrenalina puede provocar arritmias, alargamiento del intervalo QT, prolongar la isquemia o provocar vasoespasmo, por lo que su utilización en el síndrome de Kounis es arriesgada ${ }^{7,8}$. Los beta bloqueantes pueden empeorar el espasmo coronario y disminuir la acción de la adrenalina en el caso de que fuese necesario emplearla para la anafilaxia; si existe hipotensión y toma previa de betabloqueantes el tratamiento de elección sería el glucagón porque su efecto inotropo y cronotropo no está mediado por receptores beta-adrenérgicos; la dosis a utilizar en adultos sería de 1 a 2 mg pudiéndose repetir a los cinco minutos en caso de escasa respuesta ${ }^{6}$. Tratar los síntomas alérgicos exclusivamente puede ser suficiente cuando estamos ante un SK tipo I como sucedió en el primer caso descrito; sin embargo en pacientes con patología coronaria previa se deben tratar también los síntomas cardiacos ${ }^{5,7,9,10}$. La paciente del segundo caso clínico estuvo doblemente antiagregada con ácido acetil salicílico y clopidogrel sin que se evidenciasen complicaciones; no obstante la utilidad del AAS es desconocida en estos pacientes puesto que puede agravar una anafilaxia o incluso ser causa de una reacción alérgica ${ }^{3}$. En nuestra paciente, puesto que la reacción fue con un AINE se debería realizar una prueba de exposición controlada dado que la reactividad cruzada a priori es desconocida. Cuando el uso de ácido acetil salicílico sea imprescindible, debe administrarse en una unidad de cuidados intensivos ${ }^{4}$. Los pacientes con SK tipo II y alergia a aspirina conocida, pueden ser candidatos a una desensibilización.

Se deben realizar más estudios para conocer la epidemiología, diagnóstico y tratamiento óptimo de un síndrome que pasados 20 años de su descripción inicial continúa siendo un gran desconocido.

\section{Bibliografía}

1. Kounis NG, Zavras GM. Histamine-induced coronary artery spasm: the concept of allergic angina. Br J Clin Pract. 1991; 45:121-8.

2. Kounis NG, Zavras GM. Allergic angina and allergic myocardial infarction. Circulation. 1996; 94:1789.

3. Rico Cepeda P, Palencia Herrejón E, Rodriguez Aguirrebabiria MM. Síndrome de Kounis Med Intensiva. 2012; 36(5):358-64.

4. Gómez Canosa MS, Castro Orjales MJ, Rodríguez Fariñas FJ, García Jiménez A, Gutiérrez Cortés JM. Tratamiento del síndrome de Kounis. Med Intensiva. 2011; 35:519-20.

5. Kounis NG. Coronary hypersensitivity disorder: The Kounis syndrome. Clin Ther. 2013 May; 35 (5):563-71

6. Fassio F, Almerigogna F. Kounis syndrome (allergic acute coronary syndrome): different views in allergologic and cardiologic literature. Intern Emerg Med (2012) 7:489-495.

7. Kounis, N.G., Kouni, S.N. and Koutsojannis, C.M. Myocardial infarction after aspirin, and Kounis syndrome. J R Soc Med. 2005; 98:296.

8. Lindstedt, K.A. and Kovanen, P.T. Mast cells in vulnerable coronary plaques: potential mechanisms linking mast cell activation to plaque erosion and rupture. Curr Opin Lipidol. 2004; 15: 567-73.

9. Kounis NG. Kounis syndrome (allergic angina and allergic myocardial infarction): a natural paradigm? Int J Cardiol 2006; 110:7-14.

10. Gázquez V, Dalmau G, Gaig P, Gómez C, Navarro S, Mercé J. Kounis syndrome: report of 5 cases. J Invest Allergol Clin Immunol 2010; 20:162-165. 